\title{
Blood Pressure and Heart Rate Variability Response to Noninvasive Ventilation in Patients with Exacerbations of Chronic Obstructive Pulmonary Disease
}

\author{
P. SKYBA, P. JOPPA, M. OROLÍN, R. TKÁČOVÁ \\ Department of Respiratory Medicine and Tuberculosis, P. J. Šafárik University and L. Pasteur \\ Teaching Hospital, Košice, Slovak Republic
}

Received June 20, 2006

Accepted September 7, 2006

On-line available December 19, 2006

\begin{abstract}
Summary
Sympathetic activation and parasympathetic withdrawal are commonly observed during acute exacerbations of chronic obstructive pulmonary disease (COPD). We have demonstrated previously that noninvasive positive-pressure ventilation (NPPV) improves parasympathetic neural control of heart rate in patients with obstructive sleep apnea. We hypothesized that NPPV may exert such beneficial effects in COPD as well. Therefore, we assessed the acute effects of NPPV on systemic blood pressure and indexes of heart rate variability (HRV) in 23 patients with acute exacerbations of COPD. The measurements of HRV in the frequency domain were computed by an autoregressive spectral technique. The use of NPPV resulted in significant increases of oxygen saturation (from $89.2 \pm 1.0$ to $92.4 \pm 0.9 \%, p<0.001$ ) in association with reductions in systolic and diastolic blood pressures and heart rate (from $147 \pm 3$ to $138 \pm 3 \mathrm{~mm} \mathrm{Hg}$, from $86 \pm 2$ to $81 \pm 2 \mathrm{~mm} \mathrm{Hg}$, from $85 \pm 3$ to $75 \pm 2 \mathrm{bpm}, \mathrm{p}<0.001$ for all variables), and increases in ln-transformed high frequency band of HRV (from $6.4 \pm 0.5$ to $7.4 \pm 0.6 \mathrm{~ms}^{2} / \mathrm{Hz}, \mathrm{p}<0.01$ ). Reductions in heart rate and increases in $\ln$ transformed HF band persisted after NPPV withdrawal. In conclusion, these findings suggest that NPPV may cause improvements in the neural control of heart rate in patients with acute exacerbations of COPD.
\end{abstract}

\section{Key words}

Chronic obstructive pulmonary disease $\bullet$ Heart rate variability $\bullet$ Autonomic nervous system

\section{Introduction}

Impaired autonomic regulation of heart rate was observed in both hypoxemic and normoxemic patients with chronic obstructive pulmonary disease (COPD) (Volterrani et al. 1994, Stein et al. 1998, Scalvini et al. 1999, Tukek et al. 2003). Moreover, sympathetic activation and parasympathetic withdrawal seem to be associated with worse prognosis in such patients (Stein et al. 1998, Tukek et al. 2003). Stein et al. (1998) have documented that reduced daytime high-frequency spectral power was associated with reduced forced expiratory volume in one second $\left(\mathrm{FEV}_{1}\right)$ in COPD patients with $\mathrm{PiZ}$ $\alpha 1$-antitrypsin deficiency. In addition, association between disturbances in heart rate variability (HRV) and increased sympathetic activation were shown to be 
related to increased frequency of severe cardiac arrhythmias (Tukek et al. 2003). Although the use of noninvasive positive-pressure ventilation (NPPV) has become increasingly common in the course of acute exacerbations of COPD since it obviates the need for mechanical ventilation and improves survival (Brochard et al. 1995, Kramer et al. 1995, Plant et al. 2000, 2001, Lightowler et al. 2003), its hemodynamic effects and the effects on cardiac autonomic control in patients with acute exacerbations of COPD are poorly understood (Summers et al. 2002).

In a recent randomized controlled trial, Keenan et al. (2005) observed reductions in dyspnea scores as soon as one hour after initiaton of NPPV in patients with milder COPD exacerbations. In addition, we demonstrated previously that positive pressure ventilation acutely increases baroreflex sensitivity of the heart rate in association with reductions of systemic blood pressure in patients with obstructive sleep apnea and the heart failure (Tkáčová et al. 2000). Since NPPV has the potential to improve sympatho-vagal control of the heart rate in nonCOPD disorders including acute cardiogenic pulmonary edema (Tkáčová et al. 2000, Khoo et al. 2001, Domenighetti et al. 2002, Bonsignore et al. 2006), it is conceivable to assume that the addition of NPPV to standard therapy might improve the parasympathetic control of heart rate in patients with acute exacerbations of COPD as well. Therefore, the aim of the present study was to evaluate the acute effects of NPPV on systemic blood presure and heart rate variability in patients with acute exacerbations of COPD.

\section{Methods}

Patients with acute exacerbations of COPD were consecutively recruited to the study at the Department for Respiratory Disorders and Tuberculosis at the L. Pasteur Teaching Hospital (Košice, Slovakia), which is an academic, tertiary-care teaching hospital. All patients had COPD according to the American Thoracic Society/European Respiratory Society guidelines (Pauwels et al. 2001). Exclusion criteria were respiratory arrest, decreased level of consciousness, severe exacerbation of COPD requiring intubation according to GOLD guidelines (Pauwels et al. 2001), neurological diseases, atrial fibrillation, overt cardiac failure and/or hemodynamic instability, malignancy, and severe endocrine, hepatic or renal diseases. None of the studied patients were receiving autonomically active medications other than inhaled $\beta$-agonist and/or anticholinergic agents.

Pulmonary function tests were evaluated with the use of body plethysmography (Jaeger, Germany). All pulmonary function testing was performed according to the European Respiratory Society standards with the patients in a sitting position by the same technician in order to ensure consistency of the technique. Three technically acceptable measurements were performed in each patient, and the highest value was included in the analysis. Arterial blood gases were determined in samples obtained by puncture of the radial artery in the seated patient breathing room air. Blood pressure was measured by mercury sphygmomanometer, and oxygen saturation $\left(\mathrm{SaO}_{2}\right)$ using finger pulse oximetry.

NPPV was administered using bilevel positive airway pressure ventilation (BiPAP) via the BiPAP Harmony S/T ventilator (Respironics, Murrysville, Pennsylvania). This device is capable to provide independently adjustable inspiratory and expiratory positive airway pressure. BiPAP was initiated at a level of $4 \mathrm{~cm} \mathrm{H}_{2} \mathrm{O}$ of expiratory positive airway pressure and $8 \mathrm{~cm} \mathrm{H}_{2} \mathrm{O}$ of inspiratory positive airway pressure, in a spontaneous mode.

Heart rate variability was measured by means of VariaCardio TF4 equipment (Simamedia, Olomouc, Czech Republic). The measurements of HRV in the frequency domain were computed by an autoregressive spectral technique, which provides the best spectral resolution and enables spectral decomposition with automatic identification of the low-frequency (LF) and high-frequency (HF) components of HRV. The power (i.e. the density of the beat-to-beat oscillation in the R-R interval) of HRV in the HF band has been shown to be influenced primarily by parasympathetic nervous system activity, while both parasympathetic and sympathetic activities contribute to the LF band (Pagani et al. 1997). Power in the LF band ( 0.04 to $0.15 \mathrm{~Hz})$, the HF band $(>0.15$ to $0.4 \mathrm{~Hz}$ ), and the very LF (VLF) band ( 0.00 to $<0.04 \mathrm{~Hz}$ ) (Bartels et al. 2003) were averaged over the $10 \mathrm{~min}$ of resting data acquisition in three conditions: before NPPV initiation, during NPPV therapy after $60 \mathrm{~min}$ of its application, and $30 \mathrm{~min}$ after NPPV was discontinued.

Frequency domain indexes of HRV have generally a highly skewed distribution (Stein et al. 1998). Therefore, logarithmic transformation was used to stabilize the skewness of the raw HRV data, in agreement with previous studies (Stein et al. 1998, Bartels et al. 
Table 1. Demographic characteristics and pulmonary function in the study group of patients with COPD $(n=23)$.

\begin{tabular}{ll}
\hline Variable & COPD patients \\
\hline Age (years) & $68.2 \pm 1.7$ \\
Gender (Male/Female) & $18 / 5$ \\
FVC (\% predicted) & $66.1 \pm 3.8$ \\
FEV $(\%$ predicted $)$ & $45.5 \pm 3.9$ \\
$\mathrm{FEV} / \mathrm{FVC}(\%)$ & $50.0 \pm 3.0$ \\
$\mathrm{RV} / \mathrm{TLC}(\%$ predicted $)$ & $148.3 \pm 7.6$ \\
$\mathrm{PaCO}_{2}(\mathrm{kPa})$ & $5.7 \pm 0.3$ \\
$\mathrm{PaO}_{2}(\mathrm{kPa})$ & $8.3 \pm 0.3$ \\
\hline
\end{tabular}

Data are expressed as mean \pm S.E.M. FVC, forced vital capacity, $\mathrm{FEV}_{1}$, forced expiratory volume in 1 second, RV, residual volume, $\mathrm{TLC}$, total lung capacity, $\mathrm{PaCO}_{2}$, partial pressure of carbon dioxide in arterial blood, $\mathrm{PaO}_{2}$, partial pressure of oxygen in arterial blood.

2003). Mean values of variables obtained during preNPPV, NPPV and post-NPPV periods were compared by one-way analysis of variance (ANOVA) for repeated measures, with correction for multiple comparisons by the Tukey's test. Data are expressed as mean \pm SEM. All $\mathrm{p}<0.05$ values were considered statistically significant.

\section{Results}

Twenty-three late middle-aged patients with COPD participated in the study. Their demographic characteristics, pulmonary function tests and blood gas analyses are displayed in Table 1. Pulmonary function tests revealed severe obstructive ventilatory impairment as indicated by reductions of mean $\mathrm{FEV}_{1}$ to $45.5 \pm 3.9 \%$ of predicted values. At the time of hospital admission, all patients fulfilled the criteria of suffering from acute exacerbation of COPD (Rodriguez-Roisin 2000) as indicated by a sustained deterioration of the patient's condition that was acute in onset, required a change in regular medication, and was associated with increased shortness of breath, cough and increased volume and purulence of sputum.

The use of NPPV by BiPAP ventilator for $60 \mathrm{~min}$ resulted in significant increases in mean $\mathrm{SaO}_{2}$ (from $89.2 \pm 1.0$ to $92.4 \pm 0.9 \%, \mathrm{p}<0.001$ ), that returned to pre-NPPV values following NPPV discontinuation $(90.5 \pm 1.0 \%)$. As shown in Table 2, these beneficial effects of BiPAP on oxygen saturation were accompanied by significant reductions in systolic and diastolic blood pressures while on NPPV compared to pre-NPPV that increased back to pre-NPPV values after positivepressure ventilation was discontinued (ANOVA, $\mathrm{p}<0.001$ for both variables). In addition, the heart rate significantly decreased during NPPV and remained lower also during the post-NPPV period compared to pre-NPPV ( $p<0.001)$.

The application of NPPV did not result in any significant changes in the power spectral density of LF band in the frequency-domain analysis of heart rate (Table 2). However, ln-transformed LF band was significantly increased following NPPV discontinuation in comparison with pre-NPPV values (ANOVA, $\mathrm{p}=0.011$, Table 2). In contrast, ln-transformed HF band reflecting the cardiac vagal modulation increased from pre-NPPV to NPPV, and also remained increased following NPPV discontinuation (ANOVA, $p=0.004$ ). No significant changes were observed in ln-transformed VLF band while on NPPV or after its removal (Table 2).

Table 2. Blood pressure, heart rate and power spectral density of heart rate variability indexes before noninvasive positive-pressure ventilation initiation (Pre-NPPV), during NPPV therapy after 60 min of its application (NPPV), and 30 min after NPPV was discontinued (Post-NPPV).

\begin{tabular}{lllll}
\hline Variable & Pre-NPPV & NPPV & Post-NPPV & P (ANOVA) \\
\hline Systolic BP (mm Hg) & $147 \pm 3$ & $138 \pm 3^{*+}$ & $145 \pm 3$ & $<0.001$ \\
Diastolic BP (mm Hg) & $86 \pm 2$ & $81 \pm 2^{*}$ & $83 \pm 2$ & $<0.001$ \\
Heart rate (beats/min) & $85 \pm 3$ & $75 \pm 2^{*}$ & $76 \pm 3^{*}$ & $<0.001$ \\
$\ln \mathrm{LF}\left(\mathrm{ms}^{2} / \mathrm{Hz}\right)$ & $6.5 \pm 0.4$ & $7.2 \pm 0.5$ & $7.7 \pm 0.5^{*}$ & 0.011 \\
$\ln H F\left(\mathrm{~ms}^{2} / \mathrm{Hz}\right)$ & $6.4 \pm 0.5$ & $7.4 \pm 0.6^{*}$ & $7.6 \pm 0.5^{*}$ & 0.004 \\
$\ln V L F\left(\mathrm{~ms}^{2} / \mathrm{Hz}\right)$ & $4.3 \pm 0.9$ & $5.2 \pm 0.7$ & $6.3 \pm 0.8$ & 0.670
\end{tabular}

NPPV, noninvasive positive-pressure ventilation, BP, blood pressure, LF, low frequency, HF, high frequency, VLF, very low frequency. Data are expressed as mean \pm S.E.M. $* \mathrm{p}<0.05$ compared to Pre-NPPV, ${ }^{+} \mathrm{p}<0.05$ compared to Post-NPPV 


\section{Discussion}

The two major findings of our study on the physiologic effects of noninvasive ventilation in patients with acute exacerbations of COPD are that a) application NPPV using BiPAP resulted in abrupt improvements in oxygen saturation in association with reductions in systolic and diastolic blood pressure and heart rate, and b) reductions in blood pressure and heart rate were associated with increases in the power of HF domain in the spectral analysis of HRV. In addition, increases of the power in the HF domain persisted $20 \mathrm{~min}$ following removal of NPPV. In contrast, during the application of noninvasive ventilation, no changes in the power of LF domain in the spectral analysis of HRV were observed. These findings suggest that patients with acute exacerbations of COPD may benefit from noninvasive ventilation by its beneficial effects on the control of blood pressure in association with increses in cardiac parasympathetic modulation of heart rate.

The use of noninvasive positive pressure ventilation in acute exacerbations of COPD was first described by Meduri et al. (1989) and has substantially gained popularity over the last decade. Importantly, early treatment of severe respiratory failure in patients with acute exacrebations of COPD improves considerably clinical outcomes such as mortality and intubation rate (Brochard et al. 1995, Kramer et al. 1995, Plant et al. 2000, 2001). Five randomized controlled trials in patients with acute respiratory failure resulting from COPD exacerbations have consistently shown positive results with a success rate of 80-85\% (Lightowler et al. 2003). Within the first four hours of treatment, severity of dyspnea is reduced in association with improvements in blood gases and increases in $\mathrm{pH}$. Nevertheless, the role of noninvasive positive-pressure ventilation in milder forms of COPD exacerbations remains unclear (Keenan et al. 2003, 2005), and its effects on the systemic blood pressure and neurogenic control of heart rate are poorly understood (Summers et al. 2002, Domenighetti et al. 2002).

The hemodynamic effects and the effects of noninvasive ventilation on cardiac autonomic control have been extensively studied in patients with sleep apnea with or without heart failure (Tkáčová et al. 2000, Khoo et al. 2001, Bonsignore et al. 2006), and in patients with acute cardiogenic pulmonary edema (Domenighetti et al. 2002). In our previous study in patients with obstructive sleep apnea and heart failure, positive- pressure ventilation acutely increased baroreflex sensitivity of heart rate and reset the operating point for baroreflex sensitivity to a lower blood pressure indicating improvements in the neural control of heart rate (Tkáčová et al. 2000). Similarly, in patients with acute cardiogenic pulmonary edema and severe community-acquired pneumonia, noninvasive ventilation significantly reduced heart rate and mean arterial pressure (Domenighetti et al. 2002). In patients with COPD, Summers et al. (2002) described small increases in the cardiac index and stroke volume after $15 \mathrm{~min}$ of BiPAP therapy. Our present data extend these previous findings and suggests that noninvasive positive-pressure ventilation may improve hemodynamics in association with improvements in parasympathetic control of heart rate during acute exacerbations of COPD.

What is the clinical relevance of the observed reductions in systemic blood pressure and heart rate in association with increased parasympathetic modulation of heart rate in patients with COPD? Abnormalities in autonomic nervous function, depression of heart rate response to both sympathetic and vagal stimuli, and sympathetic activation resulting from hypoxemia are well described phenomena accompanying COPD (Volterrani et al. 1994, Heindl et al. 2001, Bartels et al. 2003, Chen et al. 2006). In addition, several lines of evidence indicate that sympathetic activation and parasympathetic withdrawal are associated with a worse prognosis in patients suffering from COPD. Firstly, indexes of HRV reflect the severity of obstructive airway impairment in COPD patients with $\mathrm{PiZ} \alpha 1$-antitrypsin deficiency, and may have a prognostic value in these patients as well (Stein et al. 1998). In this study, Stein et al. (1998) showed that reduced daytime high-frequency spectral power was associated with $\mathrm{FEV}_{1}$. Secondly, Tukek et al. (2003) have recently documented that patients with COPD have disturbed sympatho-vagal balance in favor of sympathetic system, and that HRV disturbances are associated with an increased frequency of cardiac arrhythmias. Autonomic disturbances secondary to COPD may also lead to increased dispersion of the QT interval, and subsequently to increased risk of severe ventricular arrhythmias (Yildiz et al. 2002).

The physiologic basis by which parasympathetic modulation of heart rate may increase during the application of NPPV was not directly approached by our study. Mechanisms involved in this effect are probably very complex since many factors could participate, including changes in $\mathrm{SaO}_{2}, \mathrm{PaCO}_{2}$, lung volumes, and 
potentially also cardiac output. Therefore, several combinations of some factors may be postulated in the observed effects of noninvasive ventilation: elimination of sympathoexcitatory and parasympatholytic stimuli such as hypoxia and hypercapnia (Bartels et al. 2000), inhibition of the sympathetic nervous system reflexively by stimulating pulmonary stretch receptors (Seals et al. 1990), and reductions in work of breathing (Brochard et al. 1990). Regardless of the underlying mechanism(s), an increase in HRV in the HF spectrum indicates improved neural control of heart rate while on NPPV. In order to determine the exact role of different potential mechanisms involved in the observed increases in parasympathetic regulation of heart rate, studies will have to be designed specifically for this purpose.

There are several limitations of the present study. First, due to its cross-sectional design, our analyses are based on measurements of blood pressure and HRV in the acute phase of COPD exacerbations only, and therefore our results cannot be extrapolated to clarify the long-term effects of noninvasive ventilation on hemodynamic variables and neural control of heart rate. Second limitation of the study is the sole use of power spectral analysis of heart rate for the assessment of sympathetic and parasympathetic control of heart rate, without concomitant direct invasive microneurographic measurements of sympathetic nerve activity. Nevertheless, despite the noninvasive nature of power spectral analysis of HRV, this measurement is considered a valuable and clinically useful method to assess changes in autonomic nervous system function (Kleiger et al. 2005) also in patients with COPD (Bartels et al. 2004) and in critical illness (Buchman et al. 2002).

In conclusion, our results indicate that in patients with acute exacerbations of COPD, NPPV acutely reduces systemic blood pressure and heart rate, in association with increases in HF power in the frequency domain of HRV. The effects of NPPV on heart rate and HF domain of HRV, which persist in the early postNPPV period, suggesting that noninvasive ventilation may potentially cause sustained improvements in the autonomic control of heart rate. Further studies are needed to analyze the potential of noninvasive ventilation to improve cardiovascular results in the course of acute exacerbations of COPD in more details.

\section{Acknowledgements}

This work was supported by operating grant $1 / 2312 / 05$ of the Ministry of Education, Slovakia, and grant 2005/5FNLPKE-01 of the Ministry of Health, Slovakia.

\section{References}

BARTELS MN, GONZALEZ JM, KIM W, DE MEERSMAN RE: Oxygen supplementation and cardiac-autonomic modulation in COPD. Chest 118: 691-696, 2000.

BARTELS MN, JELIC S, NGAI P, BASNER RC, DE MEERSMAN RE: High-frequency modulation of heart rate variability during exercise in patients with COPD. Chest 124: 863-869, 2003.

BARTELS MN, JELIC S, GONZALEZ JM, KIM W, DE MEERSMAN RE: Reproducibility of heart rate and blood pressure variability in patients with chronic obstructive pulmonary disease. Clin Auton Res 14: 194-196, 2004.

BONSIGNORE MR, PARATI G, INSALACO G, CASSTIGLIONI P, MARRONE O, ROMANO S, SALVAGGIO A, MANCIA G, BONSIGNORE G, DI RIENZO M: Baroreflex control of heart rate during sleep in severe obstructive sleep apnea: effects of acute CPAP. Eur Respir J 27: 128-135, 2006.

BROCHARD L, ISABEY D, PIQUET J, AMARO P, MANCEBO J, MESSADI AA: Reversal of exacerbations of chronic obstructive lung disease by inspiratory assistance with a face mask. $N$ Engl $J$ Med 323: 1523-1530, 1990.

BROCHARD L, MANCEBO J, WYSOCKI M, LOFASO F, CONTI G, RAUSS A, SIMONNEAU G, BENITO S, GASPARETTO A, LEMAIRE F, ISABEY D, HARF A: Noninvasive ventilation for acute exacerbations of chronic obstructive pulmonary disease. $N$ Engl J Med 333: 817-822, 1995.

BUCHMAN TG, STEIN PK, GOLDSTEIN B: Heart rate variability in critical illness and critical care. Curr Opin Crit Care 8: 311-315, 2002.

CHEN WL, CHEN GY, KUO CD: Hypoxemia and autonomic nervous dysfunction in patients with chronic obstructive pulmonary disease. Respir Med 100: 1547-1553, 2006. 
DOMENIGHETTI G, GAYER R, GENTILINI R: Noninvasive pressure support ventilation in non-COPD patients with acute cardiogenic pulmonary edema and severe community-acquired pneumonia: acute effects and outcome. Intensive Care Med 28: 1226-1232, 2002.

HEINDL S, LEHNERT M, CRIEE CP, HASENFUSS G, ANDREAS S: Marked sympathetic activation in patients with chronic respiratory failure. Am J Respir Crit Care Med 164: 597-601, 2001.

KEENAN SP, SINUFF T, COOK DJ, HILL NS: Which patients with acute exacerbations of chronic obstructive pulmonary disease benefit from noninvasive positive-pressure ventilation? Ann Intern Med 138: 861-870, 2003.

KEENAN SP, OWERS CE, MCCORMACK DG: Noninvasive positive-pressure ventilation in patients with milder chronic obstructive pulmonary disease exacerbations: A randomized controlled trial. Respir Care 50: 610-616, 2005.

KHOO MCK, BELOZEROFF V, BERRY RB, SASSON SH: Cardiac autonomic control in obstructive sleep apnea. Effects of long-term CPAP therapy. Am J Respir Crit Care Med 164: 807-812, 2001.

KLEIGER RE, STEIN PK, BIGGER JT JR: Heart rate variability: measurement and clinical utility. Ann Noninvasive Electrocardiol 10: 88-101, 2005.

KRAMER N, MEYER TJ, MEHARG J, CECE RD, HILL NS: Randomized, prospective trial of noninvasive positive pressure ventilation in acute respiratory failure. Am J Respir Crit Care Med 151: 1799-1806, 1995.

LIGHTOWLER JV, WEDZICHA JA, ELLIOTT MW, RAM FS: Non-invasive positive pressure ventilation to treat respiratory failure resulting from exacerbations of chronic obstructive pulmonary disease: Cochrane systematic review and meta-analysis. BMJ 326: 185, 2003.

MEDURI GU, CONOSCENTI CC, MENASHE P, NAIR S: Noninvasive face mask ventilation in patients with acute respiratory failure. Chest 95: 865-886, 1989.

PAGANI M, MONTANO N, PORTA A, MALLIANI A, ABBOUD FM, BIRKETT C, SOMERS VK: Relationship between spectral components of cardiovascular variabilities and direct measures of muscle sympathetic nerve activity in humans. Circulation 95: 1441-1448, 1997.

PAUWELS RA, BUIST AS, CALVERLEY PMA: Global strategy for the diagnosis, management, and prevention of chronic obstructive pulmonary disease. NHLBI/WHO Global Initiative for Chronic Obstructive Lung Disease (GOLD) Workshop Summary. Am J Respir Crit Care Med 163: 1256-1276, 2001.

PLANT PK, OWEN JL, ELLIOTT MW: Early use of non-invasive ventilation for acute exacerbations of chronic obstructive pulmonary disease on general respiratory wards: a multicentre randomised controlled trial. Lancet 355: 1931-1935, 2000.

PLANT PK, OWEN JL, ELLIOTT MW: Non-invasive ventilation in acute exacerbations of chronic obstructive pulmonary disease: long term survival and predictors of in-hospital outcome. Thorax 56: 708-712, 2001.

RODRIGUEZ-ROISIN R: Toward a consensus definition for COPD exacerbations. Chest 117: 398S-401S, 2000.

SCALVINI S, PORTA R, ZANELLI E, VOLTERRANI M, VITACCA M, PAGANI M, GIORDANO A, AMBROSINO N: Effects of oxygen on autonomic nervous system dysfunction in patients with chronic obstructive pulmonary disease. Eur Respir J 13: 119-124, 1999.

SEALS DR, SUWARNO NO, DEMPSEY JA: Influence of lung volume on sympathetic nerve discharge in normal humans. Circ Res 67: 130-141, 1990.

STEIN PK, NELSON P, ROTTMAN JN, HOWARD D, WARD SM, KLEIGER RE, SENIOR RM: Heart rate variability reflects severity of COPD in PiZ $\alpha 1$-antitrypsin deficiency. Chest 113: 327-333, 1998.

SUMMERS RL, PATCH J, KOLB JC: Effect of the initiation of noninvasive bi-level positive airway pressure on haemodynamic stability. Eur J Emerg Med 9: 37-41, 2002.

TKÁČOVÁ R, DAJANI HR, RANKIN F, FITZGERALD FS, FLORAS JS, BRADLEY TD: Continuous positive airway pressure improves nocturnal baroreflex sensitivity of patients with heart failure and obstructive sleep apnea. J Hypertens 18: 1257-1262, 2000.

TUKEK T, YILDIZ P, ATILGAN D, TUZCU V, EREN M, ERK O, DEMIREL S, AKKAYA V, DILMENER M, KORKUT F: Effect of diurnal variability of heart rate on development of arrhythmia in patients with chronic obstructive pulmonary disease. Int J Cardiol 88: 199-206, 2003. 
VOLTERRANI M, SCALVINI S, MAZZUERO G, LANFRANCHI P, COLOMBO R, CLARK AL, LEVI G: Decreased heart rate variability in patients with chronic obstructive pulmonary disease. Chest 106: 1432-1437, 1994.

YILDIZ P, TUKEK T, AKKAYA V, SOZEN AB, YILDIZ A, KORKUT F, YILMAZ V: Ventricular arrhythmias in patients with COPD are associated with QT dispersion. Chest 122: 2055-2061, 2002.

\section{Corresponding author}

Ružena Tkáčová, Department of Respiratory Medicine and Tuberculosis, L. Pasteur Teaching Hospital, Rastislavova 43, SK-04190 Košice, Slovakia. Fax: +421-556152664. E-mail: rtkacova@central.medic.upjs.sk 